\title{
Anabases
}

ANABASES Traditions et réceptions de l'Antiquité

$20 \mid 2014$

Varia

\section{Arnaud MACÉ (dir.), Le Savoir public. La vocation politique du savoir en Grèce ancienne}

\section{Germaine Aujac}

\section{(2) OpenEdition}

\section{Journals}

Édition électronique

URL : http://journals.openedition.org/anabases/5160

DOI : 10.4000/anabases.5160

ISSN : 2256-9421

\section{Éditeur}

E.R.A.S.M.E.

\section{Édition imprimée}

Date de publication : 1 novembre 2014

Pagination : 423-424

ISSN : 1774-4296

\section{Référence électronique}

Germaine Aujac, "Arnaud macÉ (dir.), Le Savoir public. La vocation politique du savoir en Grèce ancienne », Anabases [En ligne], 20 | 2014, mis en ligne le 01 novembre 2014, consulté le 22 septembre 2020.

URL : http://journals.openedition.org/anabases/5160 ; DOI : https://doi.org/10.4000/anabases.5160

Ce document a été généré automatiquement le 22 septembre 2020.

(c) Anabases 


\title{
Arnaud MACÉ (dir.), Le Savoir public. La vocation politique du savoir en Grèce ancienne
}

\author{
Germaine Aujac
}

\section{RÉFÉRENCE}

Arnaud MACÉ (dir.), Le Savoir public. La vocation politique du savoir en Grèce ancienne, Besançon, Presses universitaires de Franche-Comté, 2013, 494 p.

10 euros / ISBN 978-2-84867-456-8

1 Un colloque avait réuni à Besançon, du 8 au 10 octobre 2008, des spécialistes variés autour du thème « Le Savoir Public, Savoirs collectifs et figures publiques du savoir en Grèce ancienne ». Le présent ouvrage en est tiré.

Lors d'une copieuse introduction, Arnaud Macé s'interroge sur le rôle social et politique du savoir et sur la démocratie comme extension de la publicité épistémique. Deux grandes parties structurent l'ensemble.

3 La première étudie les figures publiques du savoir, et la médiation entre le bien commun et le public. Est envisagé dans un premier temps le rôle des poètes et des adeptes de la sagesse dans la diffusion du savoir public. Pindare est à l'honneur, dont Camille Semenzato présente les savoirs. Puis c'est Eschyle avec son Prométhée, dont Claude Calame expose les savoirs techniques. Avec une grande finesse, Malika BastinHammou réfléchit sur la figure du poète comique, un professionnel du spectacle sans doute mais aussi un maitre de vérité. À côté des poètes, les philosophes eux aussi prétendent se montrer utiles à la communauté politique, comme l'indiquent olivier Renaut et Arnaud Macé. On ne saurait d'ailleurs négliger le rôle des prosateurs dans la diffusion $\mathrm{du}$ savoir auprès $\mathrm{du}$ public. Bernard Vitrac étudie les figures $d u$ mathématicien et les représentations des mathématiques en Grèce ancienne. MarieLaurence Desclos s'intéresse à la médecine et à sa publicité. Melina Tamiolaki présente 
l'historien comme figure du savoir, dans son dialogue avec le public, et illustre son propos de références à Hérodote, Thucydide et Xénophon. Laëtitia Monteils-Laeng montre, en s'appuyant sur l'image du sophiste Protagoras, les ambivalences du savoir public.

La seconde partie s'intitule : « Le peuple servi par lui-même. Les savoirs collectifs et le bien commun. » Elle est elle-même subdivisée en deux sous-parties.

5 Il est d'abord question des savoirs collectifs en représentation, ainsi que des rapports entre démocratie et savoir. La vie politique à Athènes tient souvent du spectacle, vu le rôle joué par orateurs ou démagogues dans l'exercice de la vie publique, comme le souligne Noémie Villacèque. Avec humour, Martin Steinrück évoque «l'école des parents, l'école des enfants ", montrant que dans l'Antiquité (comme de nos jours), il a pu exister un grand décalage du savoir, « où l'enfant sait plus que son père ou sa mère, et ceci dans la discipline centrale de l'apprentissage de l'époque classique ou hellénistique, la mousikè, notamment dans le domaine du chant et du rythme », et il évoque à ce propos Aristophane qui, dans les Grenouilles, figure un débat entre la nouvelle Muse et l'ancienne.

6 La fable est-elle un savoir démocratique, s'interroge Marie-Claude Charpentier ? Ésope était à coup sûr une personnalité très populaire à Athènes $a u v^{e}$ siècle av. notre ère. Les Fables, souvent considérées comme l'expression métaphorique d'une société, nous offrent d'amples renseignements sur la vie politique ancienne. Quant à Olivier Renaut, il déplore avec Platon "l'impossibilité pour celui qui possède véritablement un savoir politique de l'exercer pleinement et correctement pour l'intérêt de la cité » mais montre que Platon, au livre IV de la République, reconnaît que «la délibération sur les moyens d'administration de la cité vise le bien commun»; les gardiens doivent apprendre à diffuser leur savoir, afin de constituer une communauté unie par la concorde et par là même durable.

7 Trois conférences de Josiah Ober et les discussions qui s'ensuivent terminent cet important ouvrage. Josiah Ober, professeur en sciences politiques et lettres classiques à l'université de Stanford, travaille sur les institutions, la culture et la théorie politiques des anciens Grecs. Il a publié en 2008 Democracy and Knowledge : Innovation and Learning in Classical Athens, qui se propose de souligner l'étroite corrélation entre le développement des institutions démocratiques et la performance d'État du temps de Thucydide, Platon et Aristote. Dans la première de ces conférences, il étudie «La compétition, l'action collective et le problème du savoir utile "; la discussion qui s'ensuit, par Charles Girard, montre « ce qu'Athènes apprend à la théorie politique », et se demande si la démocratie peut être un régime efficace. La seconde conférence, "Mise en commun de l'information et convergence de l'action", attire l'interrogation de Paulin Ismard: "Réseaux sociaux et rituels civiques: comment se construit un savoir public dans l'Athènes classique?» À la troisième, «Règles codifiées et publicité ", répond Vincent Azoulay: "Ghost of the Empire : circulation du savoir et dynamique impérialiste dans l'Athènes classique. » Mais Josiah Ober a le dernier mot en réponse à ses trois commentateurs.

8 La diversité des approches, le sérieux des analyses donnent beaucoup de valeur à cet ouvrage. On peut regretter certaines absences, celle d'Homère par exemple, dont Strabon vantait « la connaissance de la vie politique » (Géogr. I, 1, 2). Mais comment être exhaustif lors d'un colloque où chacun fait le point sur ses propres recherches? Ce livre en tout cas a le grand mérite d'attirer l'attention sur la vocation politique du savoir en 
Grèce ancienne, comme l'indique son sous-titre. Il ouvre maintes perspectives originales et contribuera à faire mieux connaître la vie publique dans l'Athènes ancienne.

\section{AUTEURS}

\section{GERMAINE AUJAC}

Université de Toulouse - Jean Jaurès (UT2J)

aujac.germaine@wanadoo.fr 